\title{
Practical management of pain in sickling disorders
}

\author{
Richard Grundy, Richard Howard, Jane Evans
}

Sickle cell disease affects approximately 5000 people in the UK predominantly of African and Afro-Caribbean origin. ${ }^{1}$ The majority of those affected live in inner city areas; for example it is the most common inherited condition in the City and Hackney district of London. There is a high morbidity and mortality in children with up to $10 \%$ dying within the first 10 years of life. ${ }^{2}$ Sickle cell related pain is the most frequent problem experienced by young patients. ${ }^{134}$ In a carefully documented home study of children with homozygous sickle cell disease the number of painful crises averaged 3.9 per patient per year, not all requiring hospital admission but severe enough to undermine normal activities. ${ }^{5}$ The disease varies in severity depending in part on the genetic abnormality inherited; those homozygous for the classical sickle mutation tend to have the greatest frequency of painful episodes followed by sickle $\beta^{\circ}$ thalassaemia, haemoglobin SC disease, and sickle $\beta^{+}$thalassaemia. ${ }^{6}$ However within each genotype the number of painful episodes experienced per year varies widely. $^{6}$ A recent large study found that approximately $25 \%$ of those with homozygous sickle cell anaemia have severe disease with three to 10 admissions per year, $50 \%$ have at least one severe episode per year, and the remainder rarely present with sickle cell related pain. ${ }^{6}$ The inpatient stay is usually between 5-10 days in hospital, but may be longer making this complication a considerable source of morbidity and consumer of resources. ${ }^{6-8}$

Sickle cell related pain occurs as an acute circumscribed event within the context of a chronic illness presenting a clinical challenge whose management is controversial. ${ }^{910}$ There is substantial evidence that pain is undertreated in children, not least in those with sickling disorders. ${ }^{11-13}$ This may occur due to fear of inducing addiction or a failure to understand the importance of treating pain in children and is hindered by the complexity of assessing its severity. ${ }^{11-13}$ Pain in children should be judiciously and competently treated in order to minimise immediate complications and allow normal emotional and physical development. ${ }^{14}$ The increased life expectancy for those with sickling disorders means that the long term consequences of treating sickle cell related pain in children needs to be carefully considered in terms of development, function, and quality of life.
This is best achieved within the context of a multidisciplinary team approach.

\section{Pathophysiology}

Sickle cell related pain is thought to be due to vaso-occlusion. The unstable haemoglobin of sickling disorders polymerises when deoxygenated to form the classical inflexible sickle shaped cells, these slow capillary blood flow causing local hypoxaemia and further sickling. ${ }^{4}$ Acceleration of this process may occlude collateral flow resulting in ischaemia, infarction, and tissue necrosis. ${ }^{15} \mathrm{~A}$ recent alternative hypothesis is that painful crises may be initiated by a centrally mediated reflex shunting blood away from the bone marrow resulting in avascular necrosis. ${ }^{16}$ Precipitating factors are legion, examples include infection, dehydration, exposure to cold, stress, and tiredness although many episodes are unexplained. ${ }^{34717}$ The mechanisms underlying the clinical variability of sickling diseases is ill understood but involves the interaction of genotype, haematological indices, rheological, endothelial, and microvascular factors. ${ }^{4}$

The widely held belief that the fetus and neonate do not experience pain has been refuted by evidence documenting the considerable and deleterious physiological, hormonal, and metabolic changes induced by pain and stress. These effects can be ameliorated by adequate analgesia. ${ }^{1819}$ It is possible that similar adverse physiological effects may occur in sickle cell related pain further complicated by the emotional associations of this sensation. This hypothesis supports the argument for adequate analgesia during a painful episode but clearly further research is required.

\section{Natural history}

The ability of a child to express pain is affected by racial and cultural factors and past experiences. Some appreciation of the nature and severity of painful episodes may be gained from African tribal names for sickle cell disease, 'hemkom' (Adangme tribe) meaning body biting and 'nuidudui' (Ewe tribe) body chewing. ${ }^{20}$ The onomatopoeia of 'nuidudui' and 'chwechweechwe' (Ga tribe) reflecting the relentless and repetitive gnawing pains in bones and joints. ${ }^{20}$ Pain arising from a serious injury or postoperatively is often considered less severe than sickle related pain. 
Strategies for coping with pain

(1) Age 6 months -4 years

i. Parental education

ii. Encourage home management where and when possible

(2) Age 4-7 years

controlled analgesia for severe pain

i. Introduce patient and continue parent education

ii. Teach pain coping skills

iii. Introduce PCA when well, that is in clinic

iv. Continue to encourage and support home care

(3) Age 8-16 years

i. Continue the above basis tenets of care and education

ii. Support patient and family

iii. Liaise with school and provide educational information

Sickle cell related pain predominantly affects the younger population. ${ }^{4}$ The painful crisis is unpredictable. It varies in timing, duration, location, and intensity both between and within each episode. ${ }^{421}$ The episode ends with a return to the status quo. A prodromal period often occurs that either leads to severe pain or grumbles on for a few days before receding; conversely severe pain may start abruptly. ${ }^{22}$ Children tend to present with limb pain, the swollen painful joints of dactylitis being a classic clinical finding, older patients present with juxta articular pain from larger joints. $^{3}$ A rigid abdomen indistinguishable from that seen in acute surgical conditions is not uncommon in the older child. ${ }^{23}$ It usually coexists with pain elsewhere, bowel sounds are often normal, and vomiting rare; careful and regular assessment by surgeon and paediatrician is necessary.

\section{Management}

All children presenting with an acute painful episode need careful evaluation looking for other complications of sickle cell disease. ${ }^{3}$ General medical management includes keeping the child warm, rested, and ensuring adequate hydration; the latter is usually given intravenously $(80-100 \mathrm{ml} / \mathrm{kg} /$ day $)$. Fever and a raised white cell count are common findings, and although they are more likely to be due to vaso-occlusion broad spectrum antibiotics should be given until blood cultures are known to be negative. Oxygen is indicated only if there is evidence of hypoxaemia as inappropriate use may down regulate erythropoietin production. ${ }^{24}$ There is little evidence that blood transfusion influences the course of the crisis unless complicated by the girdle syndrome or sickle chest disease. A transfusion programme may be appropriate for those with disabling repeated crises, although the long term complications of iron overload and risk of alloimmunisation need to be considered carefully. ${ }^{3}$

It is thought that genetic and physiological variables probably determine the severity of the vaso-occlusive crises with psychological, social, and cultural factors influencing the perception and ability to cope with pain. A multidisciplinary approach to sickle cell related pain is thus required. This includes the stepwise introduction of analgesia combined with age appropriate cognitive and behavioural strategies for coping with pain (see table). ${ }^{25}$

\section{Analgesia}

Milder painful crises can often be managed at home with rest, warmth, hydration, and oral analgesics. Regular administration of paracetamol (12 mg/kg every four to six hours), nonsteroidal anti-inflamatory drugs such as ibuprofen $5 \mathrm{mg} / \mathrm{kg}$ every six hours, or codeine phosphate $1 \mathrm{mg} / \mathrm{kg}$ every four to six hours, may contain such crises.

Children whose pain cannot be managed at home present to the accident and emergency department of their local hospital. It is important to give priority to such patients and aim to ease their pain within 30 minutes of admission. Delay in being seen is a source of frustration and anger at a difficult time for the child and the parent. ${ }^{22}$ Where possible the child should be seen by a member of the haematology team thus providing reassurance and continuity of care. When pain is severe an opioid should be prescribed. Traditionally pethidine has been used, however, accumulation of the metabolite norpethidine has been reported to cause convulsions suggesting that this drug should be avoided in patients with sickle cell disease. ${ }^{8}$ Morphine is suitable and initially may be given orally; if this route is inappropriate or too slow then it is best given either intravenously or subcutaneously. There is little indication for intramuscular administration. ${ }^{26}$ Concerns about drug induced respiratory depression leading to an acute chest syndrome or of drug dependence are not supported in the literature or in practice provided management is appropriate. ${ }^{102728}$ Pain arising from rib infarction, infection, overhydration, or pulmonary intravascular sickling are more likely to lead to this complication. ${ }^{29-31}$

Postoperative studies have demonstrated that analgesia is often inadequately given and acceptable pain relief rarely obtained. ${ }^{32}$ Furthermore many children will not actively seek treatment for pain. In sickle cell related pain the opioid dose required to achieve pain relief varies considerably within each painful episode, from one episode to another and between individual patients. ${ }^{21}$ Continuous infusions of opioid have improved this situation, being effective and widely used. ${ }^{821} 28$ The recent introduction of patient controlled analgesia (PCA) in clinical practice provides several advantages for sickle cell related pain. The patient can administer a predefined bolus of analgesia at the time of an exacerbation of the pain or when the analgesic effect is wearing off. This avoids delay and allows the patient to titrate the dose of analgesic to their level of pain while using the minimum quantity of morphine. It also allows a measure of individual control over the pain, teaching self regulation and responsibility. ${ }^{33}$ Self administration reduces the possibilities for friction between patient and hospital staff by avoiding dependance on the carer to give analgesia when required and patient to justify their need. Early reports of the use of PCA in sickle cell pain suggest that both the length of time spent in the emergency department and the dose of opioid required per episode is reduced. ${ }^{11} 34$ 


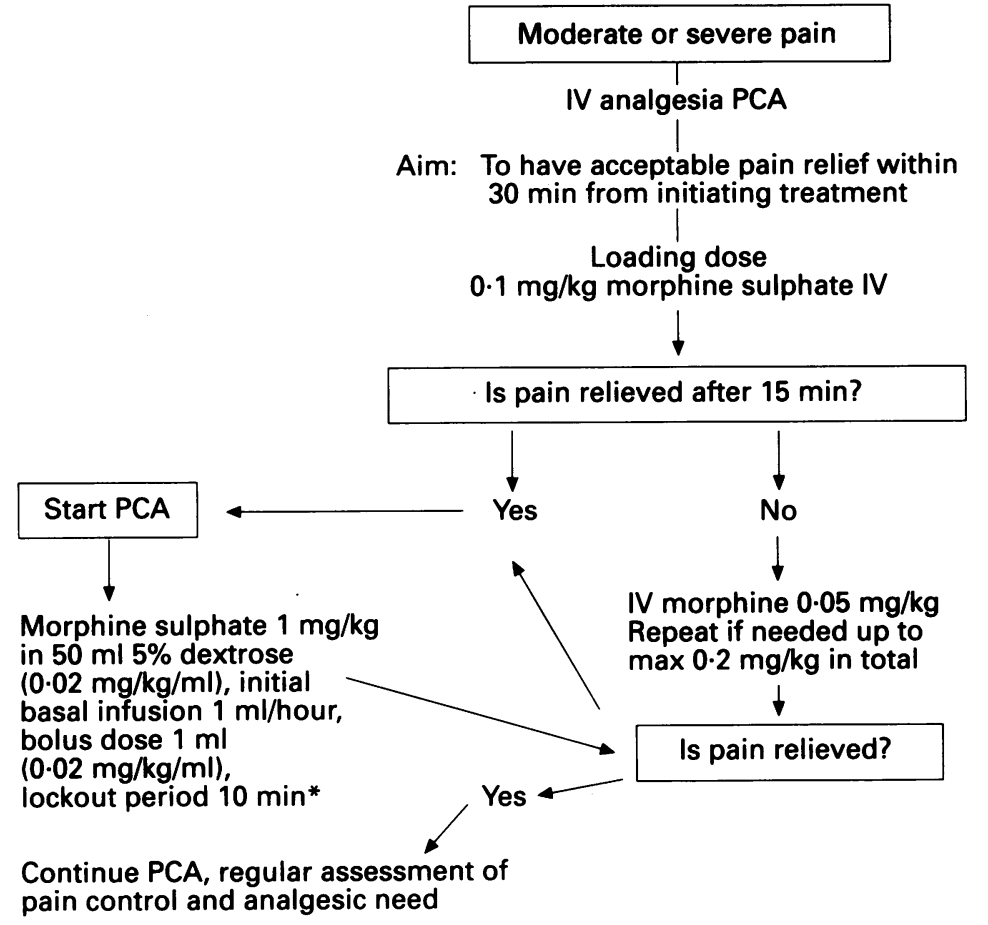

Flow chart for PCA; IV=intravenous.

* Respiration and sedation score every $15 \mathrm{~min}$, plus continuous pulse oximetry for patients with chest/abdominal pain. necessary depends on clinical circumstances. All patients are assessed hourly for quality of analgesia, degree of sedation, and respiratory rate. A rescue dose of naloxone $(0.04 \mathrm{mg} / \mathrm{kg})$ is prescribed to be given at a predetermined respiratory rate if required.

We have found that children over 6 years of age can manage PCA, although patients as young as 4 have used this method effectively. It is important that the concept and practicalities of PCA are introduced when the child is well, usually in clinic, avoiding suspicion and fear of the unknown. In a recent audit almost all of the patients expressed satisfaction with PCA as a means of pain relief. It is our subjective impression that our patients are more alert and interactive when using PCA than on continuous opioid infusions. Those who are either too young or experience difficulty with PCA receive a continuous infusion of the same preparation of morphine $(0.02 \mathrm{mg} / \mathrm{kg} / \mathrm{ml})$ given at a slightly higher rate (1-2 ml/hour); preprescribed bolus doses with a longer lockout period ( 30 minutes) can be given by either the doctor or the senior nurse caring for the child. ${ }^{35}$

PCA involves new technology and several reports have urged caution over its use. ${ }^{36} 37$ Our experience (supported by the literature) suggests that by providing adequate training, a designated team who can program the PCA machine and supervise management, clear written protocols, and careful audit of outcomes to ensure quality standards are met, a safe and effective service is possible. ${ }^{38} 39$

There is no formula for decreasing analgesia as each individual has a different recovery rate for each episode. Some may cease to need opioids at surprisingly high doses; those weaning slowly may benefit from the use of slow release preparations of oral morphine. given, which can also be repeated if neces to a maximum dose of $0.2 \mathrm{mg} / \mathrm{kg}$. Generally the first dose is sufficient. Once the patient is pain free a solution of $1 \mathrm{mg} / \mathrm{kg}$ of morphine in $50 \mathrm{ml}$ of $5 \%$ dextrose is prepared giving a concentration of $0.02 \mathrm{mg} / \mathrm{kg} / \mathrm{ml}$. The PCA pump is programmed to infuse $1 \mathrm{ml}$ per hour as a continuous background infusion and on demand bolus doses of $1 \mathrm{ml}$ at a minimum time interval of 10 minutes (termed the lockout period) are permitted. This regimen is reviewed during the first 12 hours of treatment and may need further adjustment. The background infusion is kept at the lowest comfortable dose with the patient triggering bolus doses of morphine to meet their analgesic requirement. High doses may be required. In our patient population the average dose of morphine required during the sickle cell related painful episode was $0.7 \mathrm{mg} / \mathrm{kg} /$ day compared with $0.4 \mathrm{mg} / \mathrm{kg} /$ day in postoperative children ( $R$ Howard, personal communication). An antiemetic is prescribed though vomiting is rarely a problem in our patient group. Pruritus is a relatively frequent complication but only rarely of sufficient concern to require treatment; an antihistamine may be effective in those requiring intervention. The safety of PCA lies in the negative feedback effect of self administration and the extent of monitoring

\section{Follow up}

A painful crisis lasting more than seven days requires careful re-evaluation. The possibilities of infection, especially osteomyelitis, other organic causes of pain, and psychological factors such as depression need to be considered and appropriate investigations organised. Compression fractures of the vertebrae or aseptic necrosis of the hip may lead to chronic pain and appropriate $x$ ray films may be useful.

\section{Multidisciplinary care}

Caring for a child with sickle cell disease is demanding socially, physically, and economically. Local parent support groups are beneficial and so is social support providing help for those with poor housing, economic difficulties, and other related problems. Education of the parents and family is essential and should be a continuing process in clinic and at home. Appropriate explanations for age should be given to the child lest they fear they are being punished for some misdemeanour; the use of videotapes is often helpful. Education of medical and nursing staff is an integral part of 
the multidisciplinary approach; an understanding of the nature of painful crises may improve care and management and prevent the development of adversarial relationships. The use of pain charts as part of the nursing care plan and as a point of reference for medical staff is recommended. The involvement of hospital teachers is valuable not only to assess peer related progress but also to liaise with schoolteachers obtaining or relaying information. Regular psychosocial meetings including all those involved in the care of children with sickling disorders is a vital part of this process. This provides an opportunity to discuss those who are causing concern and to organise appropriate action if necessary.

\section{Conclusion}

Successful management of sickle cell related pain is often difficult to achieve. The introduction of PCA provides a safe, effective, and important advance in care of children with sickle cell disease. However, despite this refinement of existing practice, randomised controlled trials of analgesia, its administration, and the role of behavioural and cognitive strategies are still required.

1 Brozovic M, Davies SC, Brownell AI. Acute admissions of patients with sickle cell disease who live in Britain. $B M F$ 1987; 294: 1206-8.

2 Powars DR. Natural history of sickle cell disease - the first ten years. Semin Hematol 1975; 12: 107-26.

3 Evans J. Practical management of sickle cell disease. Arch Dis Child 1989; 64: 1748-51.

4 Serjeant G. Sickle cell disease. 2nd Ed. Oxford: Oxford University Press, 1992.

5 Diggs LW, Flowers E. Sickle cell anaemia in the home environment. Clin Pediatr (Phila) 1971; 10: 697-700.

6 Platt OS, Thorington BD, Brambilla DJ, et al. Pain in sickle cell disease. Rates and risk factors. $N$ Engl f Med 1991; 325: $11-6$.

7 Shapiro BS. The management of pain in sickle cell disease. Pediatr Clin North Am 1989; 36: 1029-45.

8 Davies SC. The vaso-occlusive crisis of sickle cell disease [Editorial]. BMF 1991; 302: 1551-2.

9 Anonymous. Pain-relief in sickle cell crisis [Editorial]. Lancet 1986; ii: 320-1.

10 Brozovic M, Davies SC, Yardumian A, Bellingham A, Marsh G, Stephens AD. Pain relief in sickle cell crisis [letter]. Lancet 1986; ii: 624-5.

11 Schechter NL, Berrien FB, Katz SM. The use of patientcontrolled analgesia in adolescents with sickle cell pain
crisis: a preliminary report. Fournal of Pain and Symptom crisis: a preliminary report. Four

12 Schechter NL. The undertreatment of pain in children: an overview. Pediatr Clin North Am 1989; 36: 781-94.

13 Rana SR. Pain a subject ignored. Pediatrics 1987; 79: 309-10.
14 McGrath PJ, Craig KD. Developmental and psychological factors in children's pain. Pediatr Clin North Am 1989; 36 823-6.

15 Nagel RL, Fabry ME, Billett HH, Kaul DK. Sickle cell painful crises: a multifactorial event. Prog Clin Biol Res painful crises: a mult

16 Serjeant GR, Chalmers RM. Current concerns in haematology. 1. Is the painful crisis of sickle cell disease a 'steal' syndrome? f Clin Pathol 1990; 43: 789-91.

17 Rather SJ, Scott RB. Water sports and sickle cell anaemia Ann Intern Med 1986; 105: 971.

18 Anand KJS, Sippel WG, Aynsley-Green A. Randomised trial of fentanyl anaesthesia in preterm babies undergoing surgery: effects on the stress response. Lancet 1987; $243-8$.

19 Anand KJS, Hickey PR. Pain and its effects in the human neonate and fetus. $N$ Engl $f$ Med 1987; 317: 1321-9.

20 Konotey-Ahulu FID. The sickle cell diseases: clinical manifestations including the sickle cell crisis. Arch Intern Med 1974; 133: 611-9.

21 Sartori PC, Gordon GJ, Darbyshire PJ. Continuous papaveretum infusion for the control of pain in painful sickling crisis. Arch Dis Child 1990; 65: 1151-3.

22 Murray N, May A. Painful crises in sickle cell disease patients' perspectives. $B M 7$ 1988; $297: 452-4$.

23 Bonadio WA. Clinical features of abdominal painful crisis in sickle cell anemia. $\mathcal{F}$ Pediatr Surg 1990; 25: 301-2.

24 Embury SH, Garcia JF, Mohandas N, et al. Effects of oxygen inhalation on endogenous erythropoietin kinetics, erygen inhalation on endogenous erythropoietin kinetics, erythropoiesis and properties of blood cells

25 Masek BJ, Russo DC, Varni JW. Behavioural approaches to the management of chronic pain in children. Pediatr Clin North Am 1984; 31: 1113-29.

26 Vichinsky EP, Johnson R, Lubin BH. Multidisciplinary approach to pain management in sickle cell disease. $A m$ Pediatr Hematol Oncol 1982; 4: 328-33.

27 Sprinkle RH, Cole T, Smith S, Buchanan GR. Acute chest syndrome in children with sickle cell disease. A retrospective analysis of 100 hospitalized cases. Am $\mathcal{f}$ Pediatr Hematol Oncol 1986; 8: 105-10.

28 Cole TB, Sprinkle RH, Smith SJ, Buchanan GR Intravenous narcotic therapy for children with severe sickle cell pain crisis. Am $\mathcal{f}$ Dis Child 1986; 140 1255-9.

29 Rucknagel DL, Kalinyak KA, Gelfand MJ. Rib infarcts and acute chest syndrome in sickle cell diseases. Lancet 1991; 337: 831-3.

30 Haynes J, Allison RC. Pulmonary edema. Complication in the management of sickle cell pain crisis. $A m \mathcal{F} M e d 1986$ 80: $833-40$.

31 Davies SC, Luce PJ, Win AA, Riordan JF, Brozovic $M$ Acute chest syndrome in sickle-cell disease. Lancet 1984; i: $36-8$.

32 Mather L, Mackie J. The incidence of postoperative pain in children. Pain 1983; 15: 271-82.

33 Goldman A. Pain management. Arch Dis Child 1993; 68 423-5.

34 Gonzalez ER, Bahal N, Hansen LA, et al. Intermittent injection vs patient-controlled analgesia for sickle cell crisis pain. Comparison in patients in the emergency department. Arch Intern Med 1991; 151: 1373-8.

35 Murphy DF, Opie NJ. Nurse controlled analgesia. Anaesthesia 1991; 46: 772-4.

36 Thomas JE, Koshy M, Patterson L, Dorn L, Thomas K. Management of pain in sickle cell disease using biofeedback therapy: a preliminary study. Biofeedback Self Regul 1984; 9: 413-20.

37 Notcutt $W$. Overdose of opioid from patient controlled analgesia pumps. Br $\mathcal{F}$ Anaesth 1992; 68: 450

38 Lawrie SC, Forbes DW, Akhtar TM, Morton NS. Patientcontrolled analgesia in children. Anaesthesia 1990; 45: $1074-6$

39 Rowbotham DJ. The development and safe use of patientcontrolled analgesia. Br $\mathcal{F}$ Anaesth 1992; 68: 331-2. 